V.G. Zhekul, O.P. Smirnov, E.I. Taftaj, O.V. Khvoshchan, I.S. Shvets

\title{
PIEZOELECTRIC WAVEGUIDE SENSOR FOR MEASURING PULSE PRESSURE IN CLOSED LIQUID VOLUMES AT HIGH VOLTAGE ELECTRIC DISCHARGE
}

\begin{abstract}
Purpose. Investigations of the characteristics of pressure waves presuppose the registration of the total profile of the pressure wave at a given point in space. For these purposes, various types of "pressure to the electrical signal» transmitters (sensors) are used. Most of the common sensors are unsuitable for measuring the pulse pressure in a closed water volume at high hydrostatic pressures, in particular to study the effect of a powerful high-voltage pulse discharge on increasing the inflow of minerals and drinking water in wells. The purpose of the work was to develop antijamming piezoelectric waveguide sensor for measuring pulse pressure at a close distance from a high-voltage discharge channel in a closed volume of a liquid. Methodology. We have applied the calibration method as used as a secondary standard, the theory of electrical circuits. Results. We have selected the design and the circuit solution of the waveguide pressure sensor. We have developed a waveguide pulse-pressure sensor DTX-1 with a measuring loop. This sensor makes it possible to study the spectral characteristics of pressure waves of high-voltage pulse discharge in closed volumes of liquid at a hydrostatic pressure of up to $20 \mathrm{MPa}$ and a temperature of up to $80^{\circ} \mathrm{C}$. The sensor can be used to study pressure waves with a maximum amplitude value of up to $150 \mathrm{MPa}$ and duration of up to $80 \mu \mathrm{s}$. According to the results of the calibration, the sensitivity of the developed sensor DTX-1 with a measuring loop is 0.0346 V/MPa. Originality. We have further developed the theory of designing the waveguide piezoelectric pulse pressure sensors for measuring the pulse pressure at a close distance from a high-voltage discharge channel in a closed fluid volume by controlling the attenuation of the amplitude of the pressure signal. Practical value. We have developed, created, calibrated, used in scientific research waveguide pressure pulse sensors DTX-1. We propose sensors DTX-1 for sale in Ukraine and abroad. Sensors DTX-1 can be used to study pressure waves with a maximum amplitude value of up to $150 \mathrm{MPa}$ in closed fluid volumes at a hydrostatic pressure of up to 20 MPa and a temperature of up to $80^{\circ} \mathrm{C}$. References 10 , figures 7.
\end{abstract}

Key words: piezoelectric sensor, pulse pressure, electrical characteristics, high-voltage discharge, closed volume of liquid.

На основании проведенного анализа рынка приборов, измеряющих импульсное давление, выбрана конструкция и схемное решение помехоустойчивого волноводного датчика давления, обеспечивающего стабильность и достоверность показаний на близком расстоянии от канала высоковольтного электрического разряда в замкнутом объеме жидкости. Разработан волноводный датчик импульсного давления ДТХ-1 с измерительным шлейфом, позволяющий исследовать спектральные характеристики волн давления в закрытых объемах жсидкости при гидростатическом давлении до 20 МПа и температуре до $80^{\circ}$ С. Датчик может быть применен для изучения волн давления с максимальным амплитудным значением до 150 МПа и длительностью до 80 мкс. Согласно результатам тарировки с использованием вторичного эталона, чувствительность датчика ДТХ-1 с измерительным трактом 0,0346 В/МПа. Библ. 10, рис. 7.

Ключевые слова: пьезоэлектрический датчик, импульсное давление, электрические характеристики, высоковольтный разряд, замкнутый объем жидкости.

Introduction. A lot of modern technologies (in particular, electric discharge) use a pressure wave as the determining factor of the impact on the object being processed. The study of the spectral characteristics of such waves is of great interest and is an urgent task for any industrialized country with a developed scientific potential.

Investigations of the characteristics of pressure waves, which are generated, for example, by an electric discharge in a liquid, involve recording the total profile of the pressure wave at a given point in the volume of the liquid. For these purposes, various kinds of pressure sensors to the electric signal have been used for a long time [1-6]. Sensors based on natural (quartz, tourmaline, lithium niobate, etc.), artificially created and specially polarized in the electric field piezomaterials (piezoceramics such as barium titanate, lead titanate, lead zirconate, piezoceramics, etc.) are the most widely used in measuring the pulse pressures.

At the Institute of Impulse Processes and Technologies (IIPT) of the National Academy of Sciences of Ukraine, which is engaged in the development and implementation of various electric discharge technologies, various means of recording pulsed pressures have been used for many years in carrying out research. Among them are piezoelectric pressure sensors by the known in the field of creating measuring acoustic equipment the Danish Company «Brüel \& Kjær» [7]. In addition, the IIPT developed and manufactured its own pressure sensors based on various types of piezoceramics $[5,8]$. Most of the earlier studies were related to the measurement of pressures in open volumes of liquid at considerable distances from the discharge channel. This circumstance significantly reduced the requirements for the design of the sensor and some of its parameters (the amplitude of the measured pulse pressure, the level of permissible static liquid pressure, etc.).

Within the framework of this work, it was necessary to develop a pressure sensor for measuring the impulse pressure in a closed water volume with increased hydrostatic pressures. One of the applications of such a sensor is to study the effect of a high-voltage pulse discharge on increasing the inflow of minerals and drinking water in wells [9]. A high-pressure discharge chamber was used to calibrate and test the developed sensor (Fig. 1) which allows maintaining high hydrostatic pressure and proximity of the receiving part of the sensor

(C) V.G. Zhekul, O.P. Smirnov, E.I. Taftaj, O.V. Khvoshchan, I.S. Shvets 
to the discharge channel (source of hydrodynamic perturbation-pressure waves). The internal diameter of the discharge chamber is $120 \mathrm{~mm}$.

The proximity to the source of the pulsed pressure, the need for galvanic isolation of the sensor piezoelectric element and the circuit of the electrical circuit through which a pulsed current reaches tens of $\mathrm{kA}$, the presence of a rigid reflecting wall of the chamber on which the sensor is to be mounted increases the level of its requirements, making it impossible to use most available pressure sensors, including, hydrophones of the company «Brüel \& Kjær».

The conducted marketing researches made it possible to draw a conclusion on the principle possibility of using two pulse pressure sensors in such conditions: DPX $101-5 \mathrm{~K}$ by OMEGA Company (USA) with a sensitivity of $0.1552 \mathrm{~V} / \mathrm{MPa}$, permissible pulse pressure amplitude up to $100 \mathrm{MPa}$ and PS-02 by the GlobalTest Ltd (Russia) with sensitivity of $0.0735 \mathrm{~V} / \mathrm{MPa}$, permissible amplitude of impulse pressure up to $250 \mathrm{MPa}$.

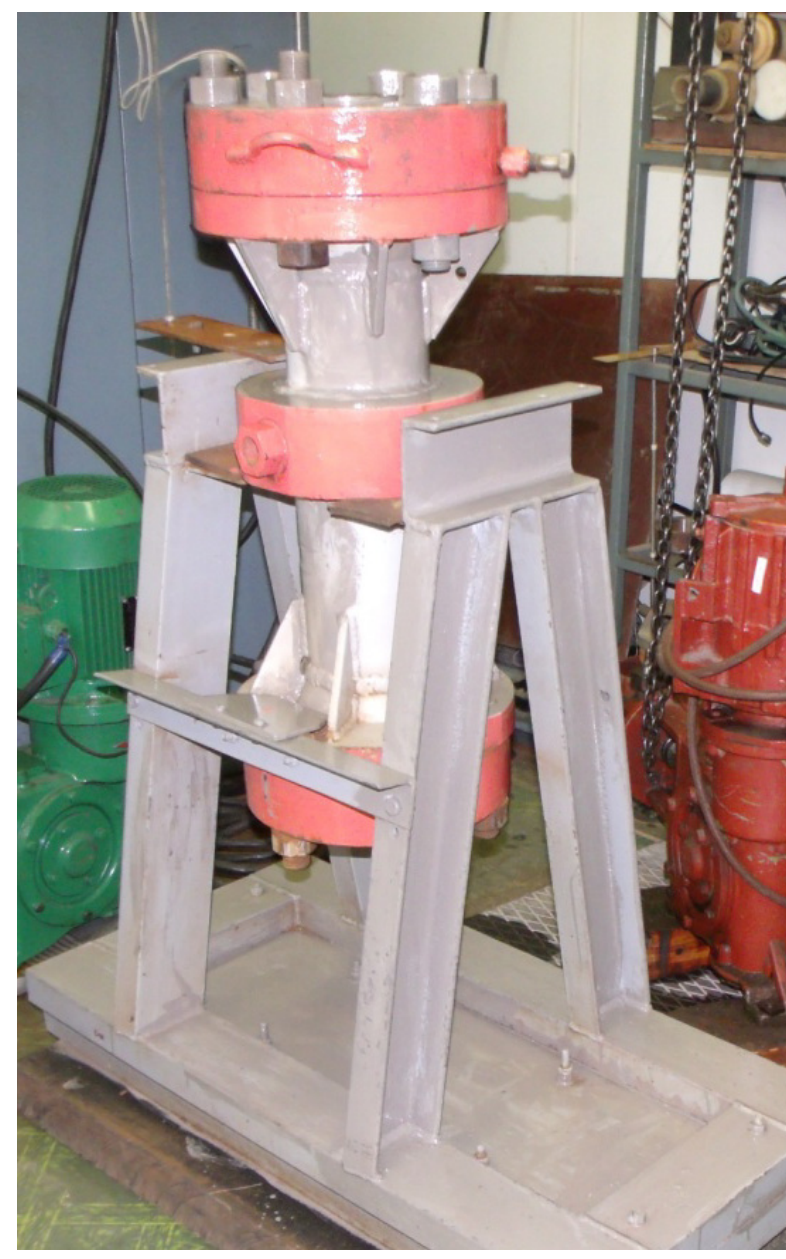

Fig. 1. High-pressure discharge chamber

During the tests of the acquired sensors, carried out by low-power electric discharges in the high-pressure discharge chamber, their significant sensitivity to the «current interference» arising due to electromagnetic interference from the high-voltage circuit was detected. Such a term for this interference is introduced due to its time and phase correlation with the oscillogram of the current flowing in the discharge circuit.
All attempts to reduce the level of interference due to additional measures (bringing of discharge and measurement circuits to one ground point, use of double screens in measurement paths, high-frequency filtering on ferrite rings) did not have a positive effect.

Oscillograms with «current guidance» are shown in Fig. 2. Due to the low sensitivity of the quartz sensors of these sensors, the amplitude of the useful signal was measured in units of volts. The amplitude of the «current guide» actually read on the oscillograms was in the range of units of volts, and was commensurable or even exceeded the useful signal from the pulse pressure sensor. This led to the conclusion that these sensors of standard design can not be used in the conditions of strong electromagnetic fields that accompany the discharge.

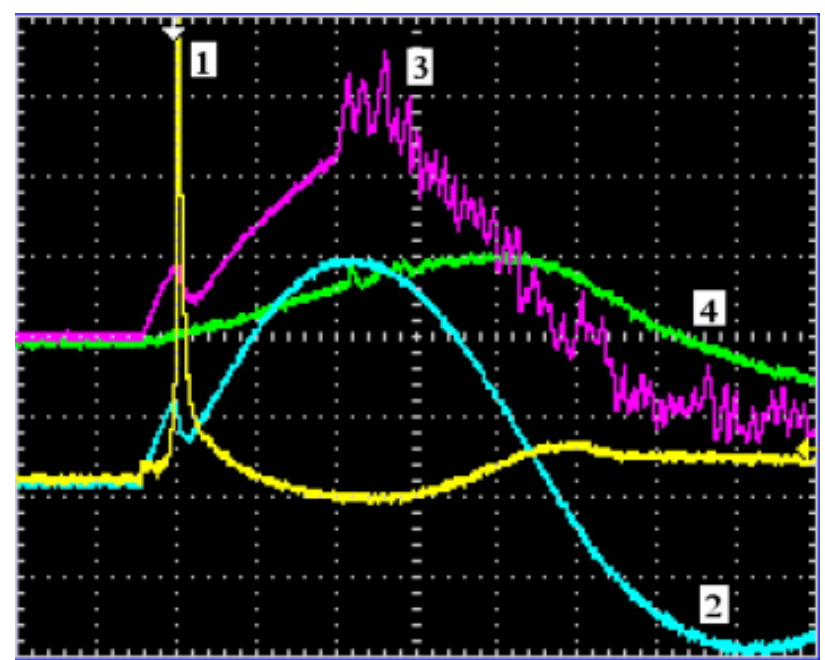

Fig. 2. The oscillogram of the pressure pulse and electrical characteristics with an electrical discharge initiated by a thin conductor: 1 - voltage across the discharge gap; 2 - current in the discharge channel; 3 - pressure wave generated by an electrical discharge in a liquid measured with a sensor pressure DPX 101-5k; 4 - pressure wave generated by an electric discharge in a liquid, measured with the help of a pressure sensor PS-02

Proceeding from the foregoing, there is a need to develop a pressure sensor that ensures the reliability of the obtained measurement results and reliability of operation in conditions of high electromagnetic fields.

The goal of the work is the development of an interference-resistant piezoelectric waveguide sensor for measuring pulsed pressure at a close distance from a highvoltage discharge channel in a closed fluid volume.

Results of sensor design. When designing a pressure sensor that meets the above requirements, a waveguide pressure sensor ВДД [5], developed earlier in the IIPT, was used as a prototype.

A distinctive feature of the developed pressure sensor should be high sensitivity, due to which the sensor generates useful signal amplitude from tens to hundreds of volts. However, a signal of this amplitude is dangerous both for the recording oscilloscope and for the transducer element of the sensor.

To reduce the level of the measuring signal, a measuring path was developed, the electrical circuit of which is shown in Fig. 3. 
When a pressure wave $P$ hits the sensor, an electric charge $Q_{1}$ is induced on its piezoceramic element with electrical capacitance $C_{1}$, and the potential difference $U_{1}$ on its plates is determined by the relation

$$
U_{1}=Q_{1} / C_{1} \text {. }
$$

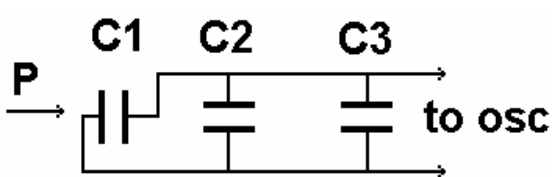

Fig. 3. Electrical circuit of the measuring path:

$\mathrm{C} 1$ - electrical capacitance of the measuring element

(piezoceramics) of the pressure sensor; $\mathrm{C} 2$ - electrical capacitance of the measuring coaxial cable; $\mathrm{C} 3$ - electrical capacitance of the additional condenser; $\mathrm{P}$ - wave pressure generated by an electric discharge in the liquid; to osc - to the oscilloscope

In the case of a capacitor with $C_{2}$ capacitance and an additional capacitor of capacitance $C_{3}$ connected to the sensor plates, the same electric charge $Q_{2}$ will provide a potential difference at the output of the $U_{\text {osc }}$ circuit, determined by the ratio

$$
U_{\text {osc }}=Q_{1} /\left(C_{1}+C_{2}+C_{3}\right) .
$$

The coefficient $k$ expressing the degree of attenuation of the useful signal and interference from the sensor is defined as the ratio

$$
k=U_{1} / U_{\text {osc }}=\left(C_{1}+C_{2}+C_{3}\right) / C_{1} .
$$

The analysis showed that the use of the ЦТС -19 piezoceramic sensor as a transducer element makes it possible to provide acceptable values of $U_{\text {osc }}$ in the pulse pressure measurement range up to $150 \mathrm{MPa}$ at a value of $k=450$.

The carried out complex of investigations made it possible to propose the design of a waveguide pressure sensor DTX-1 [10] shown in Fig. 4.

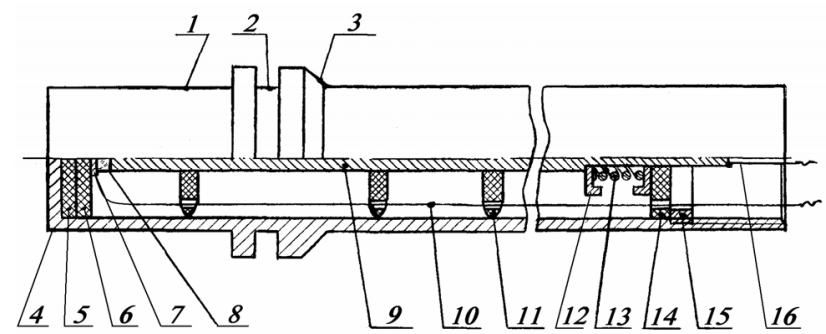

Fig. 4. Waveguide pressure sensor ДТХ-1 design

The piezoelectric waveguide pulse pressure sensor ДТХ-1 consists of a metal casing 1, on which there is a groove 2 under the sealing ring, a stop surface 3 , a receiving bottom-membrane 4 , gaskets from the vibration damping material 5, gaskets made of dielectric material with high electrical strength 6,7 , a piezoelectric element 8 , a copper waveguide 9 , conductors 10,16 , rubber shock absorbers 11, washers 12, springs 13, an insulating washer 14, nuts 15 .

The pulse pressure sensor operates as follows.

With the help of additional fastening elements, the sensor is placed in a special opening of the process chamber coaxially with the direction of passage of the pressure wave under study. The metal housing 1 of the sensor makes contact with the chamber by mechanically applying the fastening elements to the abutment surface 3 , and the sealing rubber ring in the groove 2 allows measurement in a chamber filled with liquid both at atmospheric and increased hydrostatic pressure.

The release of energy in the liquid during certain technological operations (for example, in discharge-pulse technologies) leads to the appearance of hydrodynamic perturbation and propagation of pressure waves. The pressure wave alternately passes through the liquid layer in the process chamber, the receiving bottom-membrane 4 of the sensor, the gasket from the vibration damping material 5, the gasket from the dielectric material with high electrical strength 6 , the current collector 7 , the piezoelectric cell 8 , the copper waveguide 9 .

The choice of the thickness and type of the gasket material from the vibration damping material 5 makes it possible to weaken the amplitude of the pressure wave and increase the upper limit of the pressure sensor measurement. The presence of a gasket made of a dielectric material with a high electrical strength 6 avoids an electrical contact between the housing 1 and the receiving membrane-side 4 and the piezoelectric element 8.

When a pressure wave is applied to the piezoelectric element 8 , a potential difference appears at its ends due to the phenomenon of the piezoelectric effect. Voltage with the help of soldered to a piezoelectric element 8 of a copper waveguide 9, a current collector 7 and conductors 10,16 is fed to the measuring path. The length of the copper waveguide 9 is chosen from the condition that there are no effects on the piezoelectric element of 8 pressure waves reflected from its end, which allows us to investigate pressure waves with duration of up to $80 \mu \mathrm{s}$.

The alignment of the waveguide 9 in the cylindrical body 1 is carried out by rubber shock absorbers 11 . The density of the abutment of the receiving base-membrane 4 , the gaskets 5 and 6 , the current collector 7 ensures the mechanical action of the spring 13 by means of a washer 12 , an insulating washer 14 and nuts 15 .

As a material of insulating gaskets used paronite ПМБ (State Standard 481-80) and polyethylene terephthalate ПЭТ-Э (State Standard 24234-80) was used, as a piezoelement material - ЦТС-19 (State Standard 13927-74).

The external view of the waveguide pressure sensor ДТХ-1 is shown in Fig. 5.

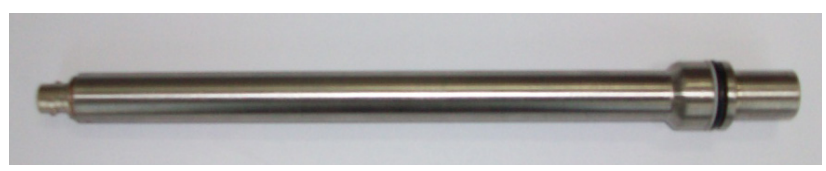

Fig. 5. The external view of the waveguide pressure sensor ДТХ-1

The waveguide pressure sensor ДТХ-1 has a significantly higher sensitivity (about two orders of magnitude) compared to the DPX 101-5K and PS-02 pressure sensors, due to this the level of the useful signal is more than an order of magnitude higher than the current-induced level. For example, in Fig. 6 shows the oscillogram of the current, voltage and signal from the 
sensor ДТХ-1 in the electric explosion of a copper conductor with a diameter of $0.14 \mathrm{~mm}$ in water.

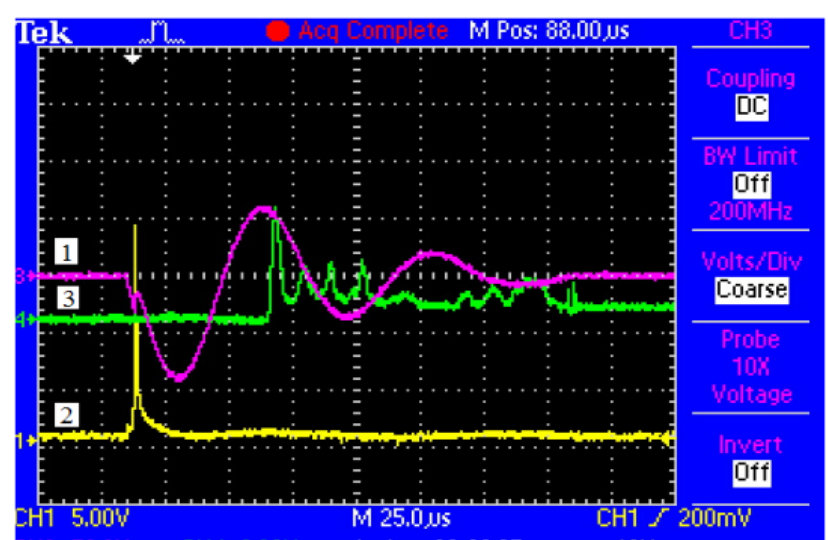

Fig. 6. Oscillogram of the pressure pulse and electrical characteristics during electrical explosion of a copper conductor (conductor diameter $-0.14 \mathrm{~mm}$, length $-0.038 \mathrm{~m}$; charging voltage $-10 \mathrm{kV}$; stored energy $-1 \mathrm{~kJ}$; hydrostatic pressure - $20 \mathrm{MPa}$ ): 1 - current in the discharge channel (inverted); 2 - voltage across the discharge gap; 3 - signal from the sensor ДТХ-1

Calibration of the waveguide pressure sensor. The calibration of the ДТХ-1 sensor was performed by comparing the calibration (reference) pressure pulses with the signals obtained with the ДТХ-1 sensor. Based on the results of the comparison, the sensitivity factor of the sensors was calculated.

As pressure calibration pulses, the data obtained with the help of a secondary reference (pressure sensor DPX 101-5K) were used with the following installation parameters: charging voltage of the capacitor bank -15 $\mathrm{kV}$; capacitance of the capacitor bank - $2.26 \mathrm{uF}$; the inductance of the circuit is $4.29 \mu \mathrm{H}$. With these loop parameters, it was possible to separate in time the «current jamming» and the useful signal of the DPX 101$5 \mathrm{~K}$ sensor.

The initiation of the discharge was carried out with a copper conductor of $0.14 \mathrm{~mm}$ in diameter and $50 \mathrm{~mm}$ in length, which increased the stability of the amplitude of the pressure wave. The hydrostatic pressure in the chamber was maintained at $10 \mathrm{MPa}$. The pressure sensor ДТХ-1 fixed pulses from five digits. The obtained results were subjected to statistical processing, the average value was found, according to which the sensitivity of the calibrated sensor was determined.

ДТХ-1 calibration was performed in conjunction with the measuring path (see Fig. 3), which has the following parameters:

- electrical capacitance of the manufactured pressure sensor ДТХ-1 C1 - $150 \mathrm{pF}$;

- electrical capacitance of measuring cable PK 50-2$16 \mathrm{~S} 2$ with length of $10 \mathrm{~m}-1166 \mathrm{pF}$;

- electrical capacitance of the load capacitor C3 $66340 \mathrm{pF}$.

Thus, the calibration of the sensor with the path consisted in determining its sensitivity when subjected to a pressure pulse of known amplitude (obtained on a certified sensor).
Fig. 7 shows the combined time profiles of the reference pulse (1) and the pulse profile recorded by the waveguide sensor ДТХ-1 (2). For convenience of comparison of the oscillograms, the amplitudes of both signals are reduced to one value. The above results (see Fig. 7) showed that the coincidence of the signals, both along the rising edge of the pressure pulse, and in the duration of its decrease is satisfactory.

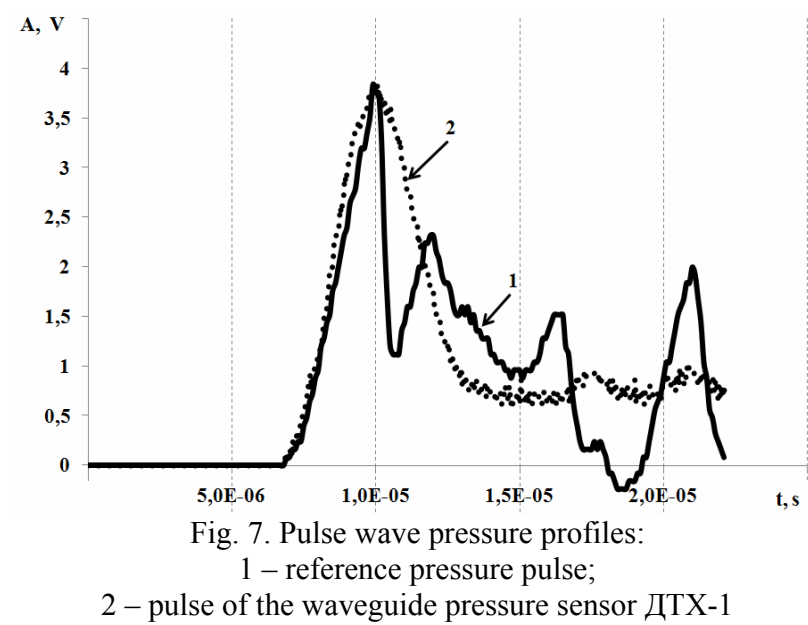

According to the calibration results, the sensitivity of the developed sensor ДТХ-1 with the measuring path is $0.0346 \mathrm{~V} / \mathrm{MPa}$.

The conducted laboratory tests showed the stability of the sensitivity of the sensor when measuring pressure waves with amplitude of up to $150 \mathrm{MPa}$ and long-term operation in the range of hydrostatic pressures (0.1-20 MPa), temperatures $(10-80){ }^{\circ} \mathrm{C}$.

The developed pressure sensors ДТХ-1 were used to record the impulse pressures when performing a number of scientific research works at the IIPT of the National Academy of Sciences of Ukraine, a prototype was delivered to the research center in France.

\section{Conclusions.}

1. A design and circuit solution of an interferenceresistant waveguide pressure sensor for electrical discharge technologies providing stability and reliability of indications at a close distance from a high-voltage discharge channel in a closed fluid volume are proposed.

2. A waveguide pulse pressure sensor ДТХ-1 with a measuring loop has been developed which makes it possible to investigate the spectral characteristics of pressure waves in a high-voltage electric discharge in closed fluid volumes at a hydrostatic pressure of up to 20 $\mathrm{MPa}$ and a temperature up to $80^{\circ} \mathrm{C}$.

3. According to the calibration results, the sensitivity of the developed sensor ДТХ-1 with the measuring path is $0.0346 \mathrm{~V} / \mathrm{MPa}$.

\section{REFERENCES}

1. Sharapov V.M., Polishchuk E.S., Koshevoi N.D. Datchiki: spravochnoe posobie [Sensors: a reference book]. Moscow, Tekhnosfera Publ., 2012. 624 p. (Rus).

2. Fomin N.A. Diagnostics of Rapidly Proceeding Processes in Fluid and Plasma Mechanics. Journal of Engineering Physics and Thermophysics, 2008, vol.81, no.1, pp. 68-81. doi: 10.1007/s10891-008-0010-y. 
3. Panich A.E. P'ezoelektricheskoe priborostroenie: sbornikv 3 tomakh [Piezoelectric instrument making: a collection in 3 volumes]. Rostov-na-Donu, SKNTs VSh Publ., 2006. (Rus). 4. Shamrakov A.L. Prospects for the development of piezoelectric sensors for fast-changing, pulsed and acoustic pressures. Sensors and systems, 2005, no.9, pp. 4-8. (Rus).

5. Beskaravainyi N.M., Pozdeev V.V. Teoreticheskie osnovy izmereniia impul'snykh davlenii $v$ zhidkikh sredakh [Theoretical basis for measuring pulsed pressures in liquid media]. Kiev, Naukova Dumka Publ., 1981. 190 p. (Rus).

6. Elkarous L., Robbe C., Pirlot M., Golinval J.-C. Dynamic calibration of piezoelectric transducers for ballistic highpressure measurement. International Journal of Metrology and Quality Engineering, 2016, vol.7, no.2, p. 201. doi: 10.1051/ijmqe/2016004.

7. Available at: https://www.bksv.com/en (accessed 22 July 2016).

8. Poklonov S.G., Zhekul V.G., Smirnov A.P. Technique and results of experimental investigations of the influence of the elastic barrier on pressure wave parameters in electric discharge in water. Surface Engineering and Applied Electrochemistry, 2007, vol.43, no. 5, pp. 350-353. doi: $10.3103 / \mathrm{S} 1068375507050079$.

9. Shvets I., Zhekul V., Poklonov S., Smirnov O., Mel'kher Ju., Litvinov V., Konotop S., Khvoshchan O., Zaloga Je. Electrodischarge method of restoration of productivity of artesian well.
Ukrainian Black Sea region agrarian science, 2013, no.3, pp. 200-205. (Ukr).

10. Taftaj E.I., Zhekul V.G., Smirnov O.P., Khvoshchan O.V., Shvets I.S. P'jezoelektrychnyj hvylevidnyj datchyk impul'snogo tysku [Piezoelectric waveguide impulse pressure sensor] Patent UA, no. u 2016 11774, 2017. (Ukr).

Received 03.08.2017

V.G. Zhekul ${ }^{1}$, Candidate of Technical Science, Senior Research Scientist,

O.P. Smirnov ${ }^{1}$, Candidate of Technical Science, Senior Research Scientist,

E.I. Taftaj ${ }^{1}$, Research Scientist,

O.V. Khvoshchan ${ }^{1}$, Candidate of Technical Science,

I.S. Shvets ${ }^{1}$, Candidate of Physics and Mathematics Sciences,

${ }^{1}$ Institute of Pulse Processes and Technologies (IPPT) of NAS of Ukraine,

43-A, Bohoyavlensky Ave., Mykolayiv, 54018, Ukraine, phone +380512224113 ,

e-mail: Smirnovap1978@gmail.com,Khvoshchan@gmail.com

How to cite this article:

Zhekul V.G., Smirnov O.P., Taftaj E.I., Khvoshchan O.V., Shvets I.S. Piezoelectric waveguide sensor for measuring pulse pressure in closed liquid volumes at high voltage electric discharge. Electrical engineering \& electromechanics, 2017, no.5, pp. 55-59. doi: 10.20998/2074-272X.2017.5.09. 